\title{
RELASI AKTIVITAS DAN BENTUK DAPUR RUMAH TINGGAL DI KAWASAN PINGGIRAN KOTA YOGYAKARTA
}

\author{
Freddy Marihot Rotua Nainggolan \\ Program Studi Teknik Arsitektur, Fakultas Arsitektur dan Desain, Universitas Kristen Duta \\ Wacana Yogyakarta \\ email:fmnainggolan@gmail.com
}

\begin{abstract}
Abstrak
Dengan globalisasi segala informasi dan teknologi dengan cepat sampai ke wilayah lain di suatu Negara. Kawasan pinggiran merupakan kawasan yang diduga kuat mengalami dampak tersebut karena adanya pemicu perubahan. Dapur adalah ruang dengan keunikan karena ruang yang berhubungan langsung dengan api dan sangat berkembang pesat dalam teknologi peralatan didalamnya yang diduga mengalami pengaruh globalisasi. Penelitian ini adalah penelitian kualitatif rasionalistik untuk melihat aktivitas dan pewadahan fungsi lewat bentuk dapur rumah tinggal di kawasan pinggiran kota Yogyakarta. Enam sampel dengan kategori fungsi rumah tinggal, langgam vernakular, memiliki dapur yang berubah dan pemilik yang tinggal dengan dua generasi atau lebih dan merupakan penduduk asli dipilih sebagai obyek penelitian. Temuan adalah penyatuan dapur dengan rumah induk melalui ruang perantara dan adaptasi kitchen work triangle dalam transformasi bentuk.
\end{abstract}

Kata kunci: dapur, aktivitas, globalisasi, kawasan pinggiran, kitchen work triangle

\begin{abstract}
Title: The Relation Between Activities and the Shape of Home Kitchen in The Suburbs of Yogyakarta

Globalization has made all information and technologies quickly reach other regions. Suburbs suspected of having such impacts caused by the influence of change. The kitchen is a room with a unique because of the space directly related to the fire and growing rapidly in technology equipment inside, that allegedly subjected to the influence of globalization. This research is qualitative rationalistic to see the activities and functions through the shape of home kitchen in the suburbs of Yogyakarta. Six samples with the functional categories of residential houses, vernacular style, has a kitchen that is changing and the owners who lived with two or more generations and are natives selected as research objects. The finding is the unification of kitchen to the main house through an intermediary space and adaptation of kitchen work triangle in transformation of form
\end{abstract}

Keywords: kitchen, activity, globalization, suburb, kitchen work triangle

\section{Pendahuluan}

Franc Roddam pada tahun 1990 memperkenalkan pertama kali ajang lomba memasak lewat MasterChef. Dipopulerkan pertama kali lewat versi Britania Raya saat ini telah menjadi kompetisi yang sangat popular di berbagai Negara. Tayangan ini menunjukkan berubahnya cara pandang tentang memasak yang dahulu merupakan kegiatan privat menjadi kegiatan yang sangat menghibur karena sentuhan entertaint maupun 
kecanggihan peralatan dan teknologi dapur.

Guardian (2013b) menyatakan bahwa globalisasi dan teknologi baru telah membuat tak terbatasnya kepemilikan data individu dan juga kepemilikan serta penggunaan data individu tersebut. Perkembagan teknologi informasi bahkan membuat batas-batas administratif suatu negara menjadi bias. Informasi dan gaya hidup dari wilayah lain disuatu negara begitu cepat sampai ke wilayah di suatu negara yang lain (Giddens, 1991). Globalisasi dan perkembangan teknologi saling memperkuat. Fenomena ini menimbulkan pertanyaan tentang pengaruh globalisasi dan teknologi terhadap transformasi dapur rumah tinggal.

Salah satu ruang dalam rumah tinggal yang diduga mengalami dampak perkembangan global adalah dapur. Dapur adalah ruang dengan keunikan karena ruang yang berhubungan langsung dengan api dan sangat berkembang pesat dalam teknologi peralatan didalamnya. Dapur merupakan ruang yang sangat penting dalam banyak rumah tinggal. Karena persiapan dan pelayanan makanan adalah aktivitas yang sangat esensial dalam kehidupan keluarga maupun individu (Julia., Emmel, dan Kathleen, 2003; dalam http://search.proquest.com/docview/21 8192191? accountid=44396). Di dalam dapur terdapat peralatan untuk mengawetkan makanan, memanaskan makanan, dan juga media elektronik sebagai pelengkap hiburan di dalam dapur. Tiga domain yang terhubung dengan aktivitas di dapur sudah teridentifikasi yaitu: 1) Menyimpan, mempersiapkan, memasak dan makan 2) Bersosialisasi dengan yang lain, dan 3) Mengorganisir kehidupan pribadi dan keluarga (Johansson, Lundberg, \& Borell, 2011).

Dalam penelitiannya untuk budaya Afrika-Amerika, Jenkins (2011) menduga salah satu ruang yang paling kompleks sebagai ruang dimana kehidupan budaya terjadi tidak terbantahkan adalah ruang dapur. Jenkins mengeksplor dapur sebagai ruang metafora yang memberi inspirasi bagi terobosan kreatif untuk transformasi pengetahuan. Banyak orang punya rasa memiliki terhadap ruang dapur, karena banyak yang memiliki memori yang indah dengan kenikmatan makanan di dapur milik keluarga masing-masing. Menurut Jenkins, dapur memiliki nilai-nilai sebagai ruang kultural.

Untuk mencari kaitan gaya hidup dan dapur, Nainggolan (2014) menemukan penyatuan ruang dapur dan ruang makan atau ruang keluarga merupakan perwujudan tingkat adaptasi yang dilakukan penghuni dengan gaya hidup modern dan simple terhadap pola ruang rumah tinggal di Merapi View.

Aktivitas dan perkembangan gaya hidup manusia mendorong kecenderungan hidup semakin simple yang sangat kuat dipengaruhi oleh kemajuan teknologi yang semakin memanjakan kehidupan manusia. Terkait perubahan gaya hidup, Margana dan Nursam (2010) mengungkapkan karakteristik dari sebuah kota yang secara mencolok dapat membedakan dengan masyarakat non perkotaan adalah gaya hidup dari masyarakatnya. Latar belakang profesi, kemudahan akses transportasi, komunikasi dan berbagai fasilitas publik lainnya melahirkan perilaku dan gaya hidup yang khas. Demikian pula dengan tingkat pendidikan dan ekonomi yang berbeda semakin 
mempermudah mereka untuk beradaptasi dengan elemen-elemen modernitas.

\section{Perkembangan Dapur}

Sejarah dapur adalah ruang terpisah atau ruang lain untuk memasak atau persiapan makanan. Setelah orang Romawi meninggalkan Inggris pada tahun 407, seni kuliner dilupakan. Makanan sering dimasak di luar ruangan pada kuali. Hal ini untuk menghindari resiko kebakaran dan untuk menjaga bau pada rumah. Ketika memasak pertama kali pindah di dalam ruangan, dilakukan di ruang umum, di perapian, atau bahkan lebih awal di lantai di tengah ruangan (Gambar 3) (Kitchen, 2011)

Di Indonesia secara khusus dalam budaya Jawa menurut Suparlan (1986), konsep tentang sistem klasifikasi mengenai alam semesta dan isinya terdapat konsep dikotomi antara yang baik dan buruk, bersih dan kotor. Oleh karena itu dalam sistem klasifikasi itu maka kakus (jamban atau kamar kecil) maupun dapur letaknya selalu di belakang. Karena dapur dianggap tempat kotor, maka dalam hal membuat bangunan dapur tidak begitu diperhatikan seperti halnya rumah induk.

Dalam dapur modern terdapat sekuen kerja yang terurut (Gambar 1): Storewash-prepare-cook-serve-eat-clearwash up. Terhubung ini semua, maka ada tiga aktivitas utama yang berhubungan dengan 3 peralatan dan di sinergikan menjadi satu kesatuan yang ergonomis. (Gambar 2) yaitu: sink, regrigerator, cooker yang direlasikan dengan aktivitas mencuci, menyimpan dan mengawetkan dan memasak (Powell, 2005)

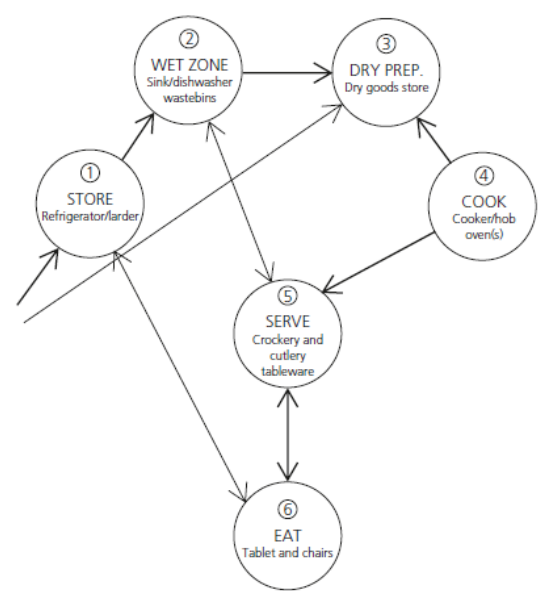

Gambar 1. Kitchen work sequence

Sumber: Powell, 2005

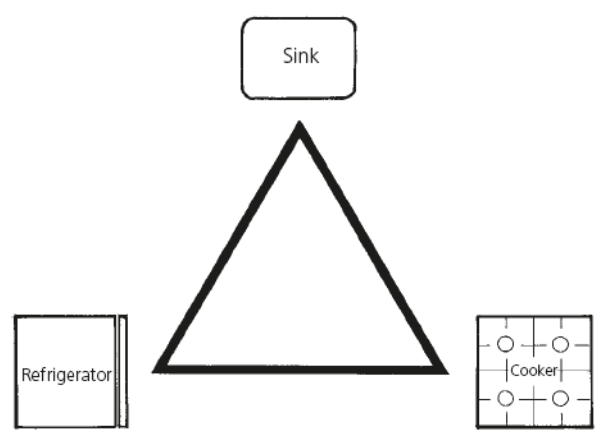

Gambar 2. Kitchen work triangle

Sumber: Powell, 2005

Saat ini orang mengharapkan, dan mendapatkan, kinerja yang lebih dari dapur mereka daripada sebelumnya. Semakin populernya konsep terintegrasinya peralatan - termasuk lemari es, mesin pencuci piring, dan laci pemanasan, yang dapat disembunyikan di belakang panel yang sesuai dengan lemari sekitarnya sejalan dengan kecenderungan membuat dapur lebih cocok sebagai ruang entertain.

Lemari tidak hanya berfungsi sebagai ruang penyimpanan tetapi juga meningkatkan dekorasi rumah (Matesi, 2006 dalam http://search.proquest.com/docview/19 4214584? accountid=44396) 


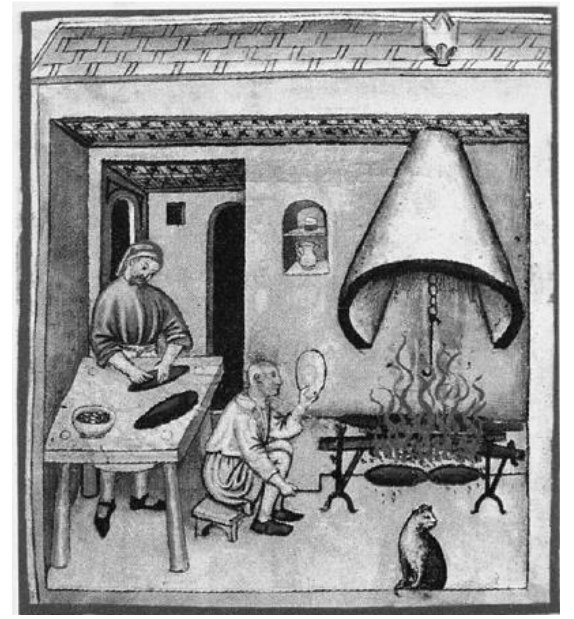

Gambar 3. Turnspit rotating meat by hand italian manuscript (15th century)

Sumber: Powell, 2005

\section{Tipologi Bentuk}

Dalam Leupen (1997) tipologi adalah kajian yang berusaha menelusuri asalusul atau awal mula terbentuknya objek-objek arsitektural. Ada tiga tahap yang harus ditempuh: Pertama, menentukan bentuk-bentuk dasar (formal structure) yang ada dalam tiap objek arsitektural. Kedua, menentukan sifat-sifat dasar (properties) yang dimiliki oleh setiap objek, berdasarkan bentuk dasar yang ada padanya. Ketiga, mempelajari proses perkembangan bentuk dasar tersebut sampai pada perwujudannya saat ini.

\section{Metode Penelitian}

Penelitian ini adalah penelitian kualitatif rasionalistik. Pada penelitian ini sampel diambil pada kawasan pinggiran Kota Yogyakarta dengan dugaan kawasan ini adalah kawasan perkembangan dari Kota Yogyakarta yang pada situasi mengalami kejenuhan. Kawasan pinggiran juga merupakan kawasan pedesaan yang terkena dampak kekotaan sehingga budaya yang ada pun mengalami dampak tersebut. Komponen- komponen yang akan diteliti tersebut adalah sebagai berikut:

1. Aspek fisik, adalah melakukan analisis bentuk dapur awal dan perubahan ke dalam bentuk dapur baru. Faktor-faktor yang akan dianalisis :

a. Fungsi/ke-ruang-an, meliputi posisi, orientasi ruang, pola hubungan ruang

b. Pelingkup, meliputi elemen pelingkup yaitu dinding dan bukaan-bukaan, lantai dan atap yang memberikan makna ketertutupan dan keterbukaan

c. Struktur, meliputi elemen konstruksi.

2. Aspek non-fisik, adalah menemukan aktivitas, dan fungsi yang terjadi.

3. Menemukan keterkaitan antara fungsi, aktivitas dan transformasi bentuk yang ada

4. Menemukan makna penerapan konsep dapur secara global dalam kitchen work triangle dengan dapur rumah tinggal di kawasan pinggiran Kota Yogyakarta.

Penentuan sampel ditentukan berdasarkan kategori :

1. Fungsi

Fungsi utama sampel sebagai dapur rumah tinggal. Dapur rumah tinggal lebih menunjukkan pengaruhpengaruh karena adaptasi secara terus menerus sepanjang hari. Rumah merupakan wilayah domestik yang mengakomodasi kehidupan sehari-hari.

2. Langgam hunian

Rumah dimana terdapat dapur yang akan diteliti adalah rumah dengan langgam vernakular. Langgam vernakular akan membedakan karakter penghuni karena langgam vernakular lebih banyak ditemukan di pedesaan. 
3. Jenis dapur

Pemilihan rumah dipersempit lagi dengan batasan terdapatnya dua jenis dapur pada rumah yaitu: dapur tradisional dengan tungku dan adanya dapur lain yang dibangun kemudian.

\section{Karakter pemilik}

Untuk membatasi maka pengamatan akan ditujukan pada rumah tinggal yang telah ditempati dengan dua generasi atau lebih. Dengan ini akan diharapkan didapat penghuni yang merupakan warga asli. Sebagai sebaran dari sampel maka dipilih pemilik dengan status ekonomi dan status sosial yang berbeda untuk melihat kemungkinan-kemungkinan hubungan antara penyesuaian dapur dengan karakter pemilik. Untuk membatasi meluasnya penelitian maka ditentukan 6 sampel yang mewakili kategori yang ditentukan pada penelitian ini. Dasar pemilihan adalah rumah tinggal yang berlokasi dekat dengan simbol-simbol global kampus (Yunus, 1987)
Pengumpulan data dilakukan berdasarkan pengamatan di lapangan (rumah yang sudah dihuni), studi literatur dari teori-teori, dan wawancara dengan pemilik rumah dan pemakai dapur sehari-hari.

\section{Hasil dan Pembahasan}

\section{Profesi dan Lokasi}

Yunus (1987) menyatakan bahwa pemicu berkembangnya kawasan pinggiran kota antara lain adanya pertumbuhan lokasi-lokasi pemukiman baru, tumbuhnya perguruan tinggi ataupun tempat-tempat kegiatan yang baru. Maka dipilihlah dua zona yang berkembang dengan pemicu perkembangan adanya perguruan tinggi, pusat perbelanjaan baru, real estate dan Stadion Maguwohardjo. Enam sampel dipilih dengan kriteria lokasi dan keluarga dengan karakter yang berbeda. Para pemilik yang disebut ini adalah pengambil keputusan pada setiap perubahan di rumah (Tabel 1).

Tabel 1.Data lokasi dan rumah tinggal

\begin{tabular}{|c|c|c|c|c|c|c|}
\hline NO & NAMA & $\begin{array}{l}\text { PRO } \\
\text { FESI }\end{array}$ & KETERANGAN & LOKASI & $\begin{array}{c}\text { KAB } \\
\text { /KOTA } \\
\end{array}$ & FAKTOR \\
\hline 1 & Kasih & $\begin{array}{l}\text { Guru } \\
\text { SMA }\end{array}$ & $\begin{array}{l}\text { Menempati rumah mulai } \\
\text { tahun } 75 \text { dan ditempati } \\
\text { oleh } 2 \text { generasi. }\end{array}$ & $\begin{array}{l}\text { Kepuhsari, } \\
\text { Krodan, } \\
\text { Maguwohardjo }\end{array}$ & Sleman & $\begin{array}{l}\text { Universitas Sanata } \\
\text { Dharma, Perumahan } \\
\text { Casa Grande, } \\
\text { Perumahan Taman } \\
\text { Cemara, Stadion } \\
\text { Maguwohardjo }\end{array}$ \\
\hline 2 & $\begin{array}{l}\text { Minto } \\
\text { Sutarjo }\end{array}$ & $\begin{array}{l}\text { Tukang } \\
\text { Batu }\end{array}$ & $\begin{array}{l}\text { Rumah dibangun oleh } \\
\text { Bapak Minto Sutarjo dan } \\
\text { dimodifikasi oleh } \\
\text { Menantu wanita setelah } \\
\text { menikah. Menantu wanita } \\
\text { memiliki peran merubah } \\
\text { tata ruang rumah }\end{array}$ & $\begin{array}{l}\text { Sarirejo, } \\
\text { Maguwohardjo }\end{array}$ & Sleman & $\begin{array}{l}\text { Lotte Mart, Ring } \\
\text { Road }\end{array}$ \\
\hline 3 & Sukirman & Petani & $\begin{array}{l}\text { Pemilik Awal Bapak } \\
\text { Ahmad Marzukih } \\
\text { seorang pegawai dan saat } \\
\text { ini ditempati hingga } \\
\text { cucu. Keputusan merubah } \\
\text { dapur atas pertimbangan } \\
\text { cucu yang sudah kuliah. }\end{array}$ & $\begin{array}{l}\text { Pugeran, } \\
\text { Maguwohardjo }\end{array}$ & Sleman & $\begin{array}{l}\text { Perumahan Casa } \\
\text { Grande, Universitas } \\
\text { Pembangunan } \\
\text { Nasional, Ringroad }\end{array}$ \\
\hline 4 & Ronorejo & Montir & $\begin{array}{l}\text { Pemilik rumah asli Pak } \\
\text { Ronorejo, kemudian } \\
\text { dirubah oleh anak yang } \\
\text { berprofesi sebagai montir }\end{array}$ & Bener & $\begin{array}{l}\text { Kota } \\
\text { Yogyakarta }\end{array}$ & $\begin{array}{l}\text { Perumahan Tirta } \\
\text { Sani, Mirota } \\
\text { Godean, Perumahan } \\
\text { Griya Indah }\end{array}$ \\
\hline 5 & $\begin{array}{l}\text { Moh } \\
\text { Baroni }\end{array}$ & Penjahit & $\begin{array}{l}\text { Anak adalah seorang } \\
\text { pegawai Swasta berusia }\end{array}$ & Trihanggo & Sleman & $\begin{array}{l}\text { Perumahan Tirta } \\
\text { Sani, Mirota }\end{array}$ \\
\hline
\end{tabular}




\begin{tabular}{|c|c|c|c|c|c|c|}
\hline NO & NAMA & $\begin{array}{l}\text { PRO } \\
\text { FESI }\end{array}$ & KETERANGAN & LOKASI & $\begin{array}{c}\text { KAB } \\
\text { /KOTA }\end{array}$ & FAKTOR \\
\hline & & & $\begin{array}{l}55 \text { tahun. Tinggal } \\
\text { dirumah ini bersama istri, } \\
\text { anak dan menantu. } \\
\text { Rumah telah ditinggali } \\
\text { oleh } 4 \text { generasi. }\end{array}$ & & & $\begin{array}{l}\text { Godean, Perumahan } \\
\text { Griya Indah }\end{array}$ \\
\hline 6 & Mugiyono & Sopir & $\begin{array}{l}\text { Berusia } 65 \text { tahun. Ibu } \\
\text { Mugiyono adalah warga } \\
\text { asli kampong ini. Rumah } \\
\text { ini ditempati oleh } 2 \\
\text { generasi. }\end{array}$ & $\begin{array}{l}\text { Ngestihardjo } \\
\text { Kasihan }\end{array}$ & Bantul & $\begin{array}{l}\text { Perumahan Tirta } \\
\text { Sani, Mirota } \\
\text { Godean, Perumahan } \\
\text { Griya Indah }\end{array}$ \\
\hline
\end{tabular}

Sumber: Data Nainggolan (2013)

\section{Bapak Kasih}

Fungsi dan aktivitas

Pemilik rumah, Bapak Kasih adalah seorang pensiunan guru SMA Babarsari. Memiliki beberapa orang anak yang saat ini sudah berkeluarga semua dan tinggal dikota-kota yang berbeda. Selain itu karena kepentingan ekonomi, maka bagian sisi barat dari rumah ini direnovasi menjadi bagian dari kost mahasiswa (Gambar 5), memiliki tiga dapur berbeda dengan kode D1, D2, D3

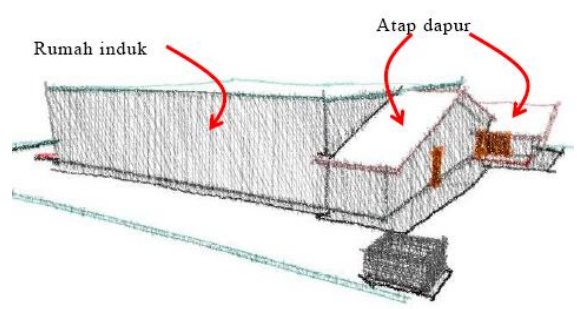

Gambar 4. Posisi dapur Bapak Kasih

Sumber: Data Nainggolan (2016)

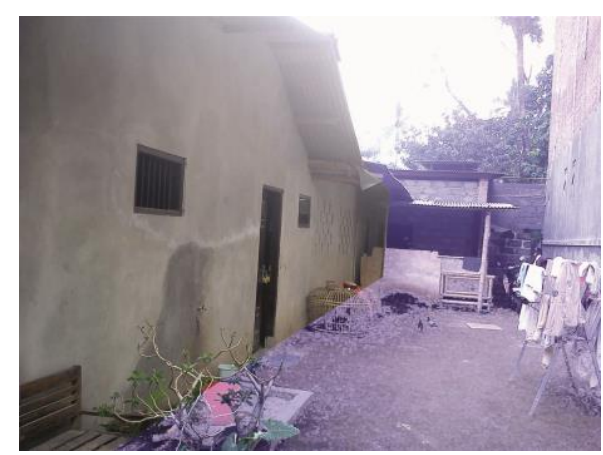

Gambar 5. Dapur baru Bapak Kasih

Sumber: Dokumentasi Nainggolan (2012)
Tabel 2. Fungsi Ruang Dapur Keluarga Bapak Kasih

\begin{tabular}{|c|c|c|c|}
\hline Dapur & $\begin{array}{l}\text { Fungsi } \\
\text { Utama }\end{array}$ & $\begin{array}{c}\text { Fungsi } \\
\text { sekunder }\end{array}$ & $\begin{array}{c}\text { Fungsi } \\
\text { Penunjang }\end{array}$ \\
\hline D1 & $\begin{array}{l}\text { Ruang } \\
\text { memanaskan } \\
\text { makanan }\end{array}$ & - & $\begin{array}{l}\text { Ruang } \\
\text { menyimpan } \\
\text { barang }\end{array}$ \\
\hline D2 & $\begin{array}{l}\text { Ruang } \\
\text { memasak } \\
\text { makanan }\end{array}$ & $\begin{array}{l}\text { Ruang } \\
\text { menyimpan } \\
\text { peralatan }\end{array}$ & $\begin{array}{l}\text { Ruang } \\
\text { menyimpan } \\
\text { kendaraan } \\
\text { roda dua }\end{array}$ \\
\hline D3 & $\begin{array}{l}\text { Ruang } \\
\text { memasak } \\
\text { makanan }\end{array}$ & $\begin{array}{l}\text { Ruang } \\
\text { mencuci } \\
\text { piring dan } \\
\text { bahan } \\
\text { makanan }\end{array}$ & $\begin{array}{l}\text { Ruang } \\
\text { menyimpan } \\
\text { barang }\end{array}$ \\
\hline
\end{tabular}

Sumber:Hasil analisis (2016)

Aktivitas yang terhubung dengan dapur yaitu, mengambil air, menyiapkan bahan bakar, memasak, menyimpan barang.

Bentuk

Tabel 3. Pembentuk ruang dapur keluarga Bapak Kasih

\begin{tabular}{|c|c|c|c|}
\hline $\begin{array}{l}\text { Da } \\
\text { pur }\end{array}$ & Keruangan & Pelingkup & Struktur \\
\hline D1 & $\begin{array}{l}\text { Menempel } \\
\text { dengan } \\
\text { rumah induk } \\
\text { dengan akses } \\
\text { dari dalam } \\
\text { dan luar } \\
\text { rumah induk. }\end{array}$ & $\begin{array}{l}\text { Tertutup lantai, } \\
\text { dinding, atap. } \\
\text { Dinding massif } \\
\text { dengan bukaan } \\
\text { ventilasi dan } \\
\text { pintu. }\end{array}$ & $\begin{array}{l}\text { Dinding } \\
\text { bata dan } \\
\text { konstruksi } \\
\text { beton } \\
\text { bertulang }\end{array}$ \\
\hline D2 & $\begin{array}{l}\text { Menempel } \\
\text { rumah induk } \\
\text { dengan akses } \\
\text { dari dalam } \\
\text { luar rumah } \\
\text { induk }\end{array}$ & $\begin{array}{l}\text { Tertutup lantai, } \\
\text { dinding, atap. } \\
\text { Bukaan adalah } \\
\text { pintu dan } \\
\text { pelubangan } \\
\text { dekoratif. }\end{array}$ & $\begin{array}{l}\text { Dinding } \\
\text { bata dan } \\
\text { konstruksi } \\
\text { beton } \\
\text { bertulang }\end{array}$ \\
\hline D3 & $\begin{array}{l}\text { Menempel } \\
\text { rumah induk } \\
\text { dengan akses } \\
\text { dari dalam } \\
\text { dan luar } \\
\text { rumah induk. }\end{array}$ & $\begin{array}{l}\text { Tertutup } \\
\text { dengan lantai, } \\
\text { dinding, atap } \\
\text { Bukaan pada } \\
\text { daun pintu dan } \\
\text { pelubangan } \\
\text { dekoratif. }\end{array}$ & $\begin{array}{l}\text { Dinding } \\
\text { bata dan } \\
\text { konstruksi } \\
\text { beton } \\
\text { bertulang }\end{array}$ \\
\hline
\end{tabular}

Sumber: Hasil analisis (2016) 
Hubungan Ruang

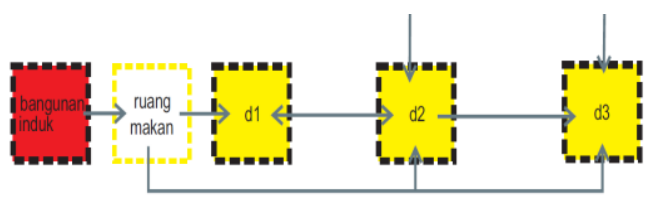

Gambar 6. Hubungan bangunan induk dan dapur keluarga Bapak Kasih

Sumber :Hasil analisis(2016)

Hubungan antara bangunan induk dan ruang-ruang dapur seperti pada Gambar 6 menunjukkan adanya ruang makan sebagai ruang perantara antara bangunan induk dan ruang-ruang dapur.

\section{Bapak Minto Sutarjo}

Fungsi dan aktivitas

Lokasi ini terletak di Dusun Sarirejo, Kelurahan Maguwohardjo Depok Sleman. Rumah ini dibangun kembali pada tahun 1980 an pada sebidang tanah yang merupakan kompensasi dari pelebaran ringroad. Melihat lokasinya kawasan ini sangat dekat dengan perbelanjaan Lotte Mart. Pelebaran ringroad pula telah memicu perkembangan transportasi dan meningkatnya nilai tanah di kawasan ini.

Tabel 4. Fungsi ruang dapur keluarga Bapak Minto Sutarjo

\begin{tabular}{clll}
\hline $\begin{array}{c}\text { Da } \\
\text { pur }\end{array}$ & $\begin{array}{l}\text { Fungsi } \\
\text { Utama }\end{array}$ & $\begin{array}{c}\text { Fungsi } \\
\text { sekunder }\end{array}$ & \multicolumn{1}{c}{$\begin{array}{c}\text { Fungsi } \\
\text { Penunjang }\end{array}$} \\
\hline D1 & Ruang & Ruang & Ruang \\
& memasak & mencuci & menyimpan \\
& makanan & piring & $\begin{array}{l}\text { barang, } \\
\text { kendaraan, dan } \\
\text { duduk bersama }\end{array}$ \\
& & &
\end{tabular}

Sumber: Hasil Analisis (2016)

Aktivitas yang terjadi adalah mengambil air, memasak, menyimpan barang.
Bentuk

Tabel 5. Pembentuk ruang dapur keluarga Bapak Minto Sutarjo

\begin{tabular}{llll}
\hline & Keruangan & Pelingkup & \multicolumn{1}{c}{ Struktur } \\
\hline D1 & Dapur bagian & Tertutup & Dinding bata \\
& dari rumah & lantai, & dan \\
induk dengan & dinding, atap & konstruksi \\
akses dari & & beton \\
& dalam dan luar & & bertulang \\
& rumah induk. & &
\end{tabular}

Sumber: Hasil analisis (2016)

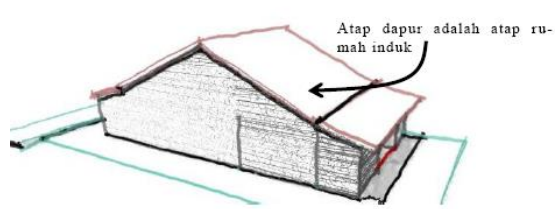

Gambar 7. Posisi dapur Bapak Minto Sutarjo

Sumber: Data Nainggolan (2016)

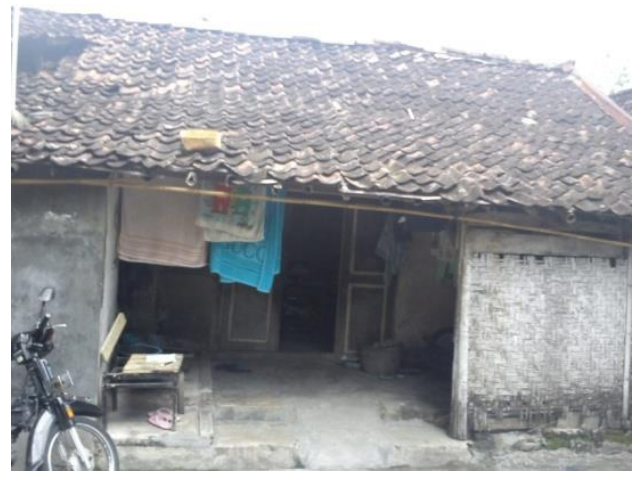

Gambar 8. Dapur lama Bapak Minto

Sutarjo

Sumber: Dokumentasi Nainggolan (2012)

Hubungan ruang

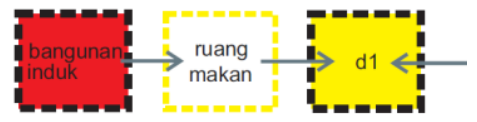

Gambar 9. Hubungan bangunan induk dan dapur keluarga Bapak Minto Sutarjo

Sumber: Hasil analisis (2016)

Hubungan antara bangunan induk dan ruang dapur seperti pada Gambar 7 menunjukkan adanya ruang makan sebagai ruang perantara antara bangunan induk dan ruang dapur. 


\section{Bapak Sukirman}

Fungsi dan aktivitas

Lokasi ini terletak di dusun Pugeran, Kelurahan Maguwohardjo, Depok, Sleman. Rumah ini dibangun pada tahun 1970-an. Banyak rumah di dusun ini yang menambahkan fasilitas kost untuk mahasiswa. Hal ini terjadi mengingat lokasi ini dekat dengan beberapa perguruan tinggi seperti Instiper, Amikom, UII dan juga adanya ruko Casa Grande memicu banyak karyawan-karyawan yang mencari kamar-kamar kost

Tabel 6. Fungsi ruang dapur keluarga Bapak Sukirman

\begin{tabular}{|c|c|c|c|}
\hline $\begin{array}{l}\text { Da } \\
\text { pur }\end{array}$ & $\begin{array}{l}\text { Fungsi } \\
\text { Utama }\end{array}$ & $\begin{array}{c}\text { Fungsi } \\
\text { sekunder }\end{array}$ & $\begin{array}{c}\text { Fungsi } \\
\text { Penunjang }\end{array}$ \\
\hline D1 & $\begin{array}{l}\text { Ruang } \\
\text { memasak } \\
\text { makanan }\end{array}$ & - & $\begin{array}{l}\text { Ruang } \\
\text { menyimpan } \\
\text { barang, duduk }\end{array}$ \\
\hline D2 & $\begin{array}{l}\text { Ruang } \\
\text { memasak } \\
\text { makanan }\end{array}$ & $\begin{array}{l}\text { Ruang } \\
\text { membersihka } \\
\text { n dan } \\
\text { mencuci } \\
\text { piring }\end{array}$ & $\begin{array}{l}\text { Ruang } \\
\text { menyimpan } \\
\text { barang }\end{array}$ \\
\hline
\end{tabular}

Sumber: Hasil Analisis (2016)

Aktivitas utama yang terhubung dengan dapur adalah mengambil air, menyediakan bahan bakar, memasak

Bentuk

Tabel 7. Pembentuk ruang dapur keluarga Bapak Sukirman

\begin{tabular}{|c|c|c|c|}
\hline & Keruangan & Pelingkup & Struktur \\
\hline D1 & $\begin{array}{l}\text { Menempel } \\
\text { dengan dinding } \\
\text { rumah induk. } \\
\text { Pencapaian } \\
\text { dari rumah } \\
\text { induk dan } \\
\text { akses dari luar. }\end{array}$ & $\begin{array}{l}\text { Tertutup } \\
\text { lantai, } \\
\text { dinding, atap }\end{array}$ & $\begin{array}{l}\text { Dinding } \\
\text { semi } \\
\text { permanen } \\
\text { dengan kayu } \\
\text { dan atap }\end{array}$ \\
\hline D2 & $\begin{array}{l}\text { Bagian dari } \\
\text { rumah induk } \\
\text { dengan akses } \\
\text { dari dalam dan } \\
\text { luar rumah } \\
\text { induk. }\end{array}$ & $\begin{array}{l}\text { Tertutup } \\
\text { lantai, } \\
\text { dinding, atap }\end{array}$ & $\begin{array}{l}\text { Dinding bata } \\
\text { dan } \\
\text { konstruksi } \\
\text { beton } \\
\text { bertulang }\end{array}$ \\
\hline
\end{tabular}

Sumber: Hasil Analisis (2016)

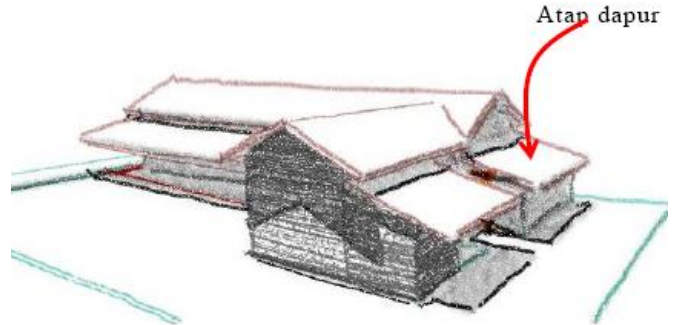

Gambar 10. Posisi dapur Bapak Sukirman Sumber: Data Nainggolan (2016)

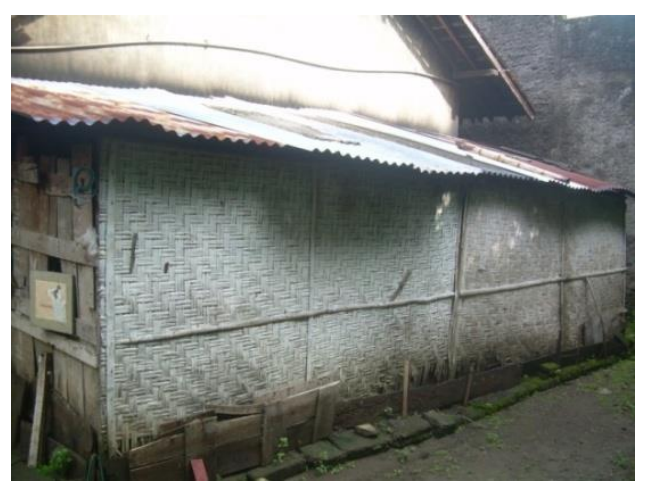

Gambar 11. Dapur lama Bapak Sukirman Sumber: Dokumentasi Nainggolan (2012)

Hubungan Ruang

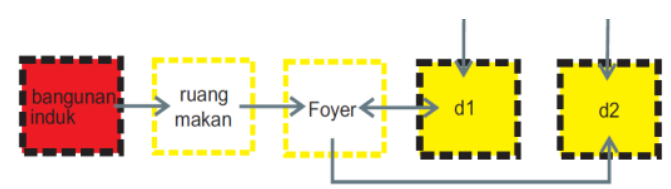

Gambar 12. Hubungan bangunan induk dan dapur keluarga Bapak Sukirman Sumber: Hasil Analisis (2016)

Hubungan antara bangunan induk dan ruang-ruang dapur seperti pada Gambar 12 menunjukkan adanya ruang makan dan ruang foyer sebagai ruang perantara antara bangunan induk dan ruang-ruang dapur.

\section{Bapak Ronorejo}

Fungsi dan aktivitas

Lokasi ini terletak di dusun Bener, Kecamatan Tegalrejo Yogyakarta. Lokasi ini menjadi menarik karena berada di perbatasan antara Kotamadya Yogyakarta dan Kabupaten Bantul serta Kabupaten Sleman. Rumah ini dibangun pada tahun 1914-an. Lokasi ini menjadi salah satu pilihan karena 
berkembangnya lokasi ini dengan adanya sekolah (SMAN 3 Bener), perguruan tinggi AA YKP, perumahanperumahan seperti Taman Griya Indah, Tirta Sani, Green Garden, dan Pusat perbelanjaan yaitu Mirota Godean.

Tabel 8. Fungsi ruang dapur keluarga Bapak Ronorejo

\begin{tabular}{clll}
\hline $\begin{array}{c}\text { Da } \\
\text { pur }\end{array}$ & $\begin{array}{l}\text { Fungsi } \\
\text { Utama }\end{array}$ & $\begin{array}{c}\text { Fungsi } \\
\text { sekunder }\end{array}$ & $\begin{array}{c}\text { Fungsi } \\
\text { Penunjang }\end{array}$ \\
\hline D1 & Ruang & Ruang & Ruang \\
& $\begin{array}{c}\text { Memasak } \\
\text { makanan }\end{array}$ & makan & $\begin{array}{l}\text { Penyimpanan } \\
\text { barang dan } \\
\text { duduk }\end{array}$ \\
\hline
\end{tabular}

Sumber: Hasil analisis (2016)

Aktivitas utama yang terhubung dengan dapur adalah mengambil air, memasak

Bentuk

Tabel 9. Pembentuk ruang dapur keluarga Bapak Ronorejo

\begin{tabular}{|c|c|c|c|}
\hline & Keruangan & Pelingkup & Struktur \\
\hline D2 & $\begin{array}{l}\text { Bagian dari } \\
\text { rumah induk } \\
\text { dengan akses } \\
\text { dari dalam dan } \\
\text { dari luar rumah } \\
\text { induk. dibatasi } \\
\text { dengan tegas } \\
\text { terhadap ruang } \\
\text { keluarga tetapi } \\
\text { tidak memiliki } \\
\text { pembatasan } \\
\text { tegas dengan } \\
\text { ruang makan. }\end{array}$ & $\begin{array}{l}\text { Tertutup } \\
\text { lantai, } \\
\text { dinding, atap. } \\
\text { Bukaan } \\
\text { sangat minim } \\
\text { hanya } \\
\text { terdapat } \\
\text { pelubangan } \\
\text { roster. }\end{array}$ & $\begin{array}{l}\text { Dinding bata } \\
\text { dan } \\
\text { konstruksi } \\
\text { beton } \\
\text { bertulang }\end{array}$ \\
\hline
\end{tabular}

Sumber: Hasil analisis (2016)

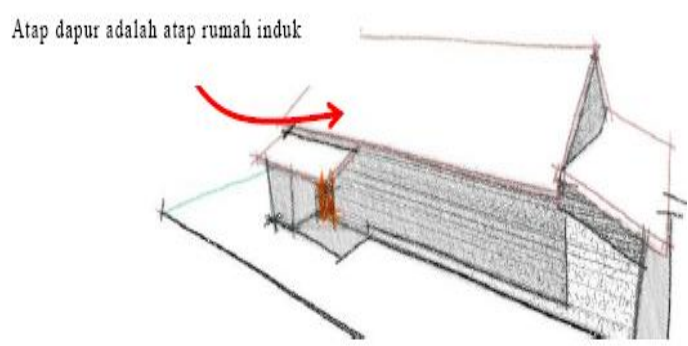

Gambar 13. Posisi dapur Bapak Ronorejo Sumber: Data Nainggolan (2016)

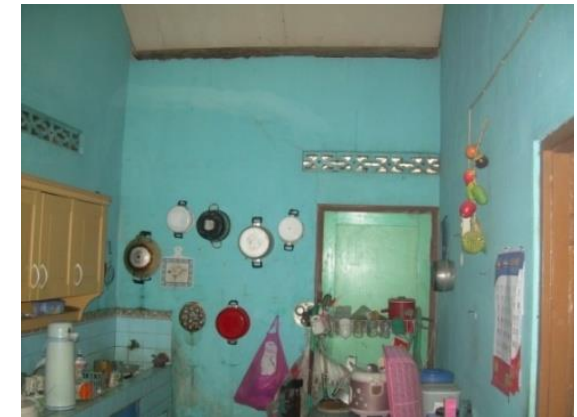

Gambar 14. Dapur baru Bapak Ronorejo Sumber: Dokumentasi Nainggolan (2012)

Hubungan ruang

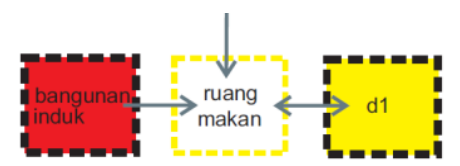

Gambar 15. Hubungan bangunan induk dan dapur keluarga Bapak Ronorejo Sumber: Hasil analisis (2016)

Hubungan antara bangunan induk dan ruang dapur seperti pada Gambar menunjukkan adanya ruang makan sebagai ruang perantara antara bangunan induk dan ruang dapur.

\section{Bapak Moh. Baroni}

Fungsi dan aktivitas

Lokasi ini terletak di dusun Trihanggo, Kecamatan Gamping Sleman.Lokasi ini menjadi menarik karena kawasan ini menjadi begitu bertumbuh diawali dengan adanya Perumahan Taman Griya Indah dan Green Garden di tahun 90 an.

Lokasi ini menjadi salah satu pilihan karena berkembangnya lokasi ini dengan adanya sekolah (SMAN 3 Bener), perguruan tinggi AA YKP, perumahan-perumahan seperti Taman Griya Indah, Tirta Sani, Green Garden, dan Pusat perbelanjaan yaitu Mirota Godean. 
Tabel 10. Fungsi ruang dapur keluarga Bapak Moh. Baroni

\begin{tabular}{clll}
\hline $\begin{array}{c}\text { Da } \\
\text { pur }\end{array}$ & $\begin{array}{l}\text { Fungsi } \\
\text { Utama }\end{array}$ & \multicolumn{1}{c}{$\begin{array}{c}\text { Fungsi } \\
\text { sekunder }\end{array}$} & $\begin{array}{c}\text { Fungsi } \\
\text { Penunjang }\end{array}$ \\
\hline D1 & Ruang & - & Ruang \\
& Memasak & & Penyimpana \\
& makanan & & Ruang \\
\hline D2 & Ruang & Ruang & Puang \\
& Memasak & Membersihkan & Penyimpana \\
& makanan & dan mencuci & n peralatan \\
& & makanan dan & \\
& & peralatan & \\
\hline
\end{tabular}

Sumber: Hasil Analisis (2016)

Aktivitas utama yang terhubung dengan dapur yaitu mengambil air, menyediakan bahan bakar, memasak.

Bentuk

Tabel 11. Pembentuk ruang dapur keluarga Bapak Moh. Baroni

\begin{tabular}{|c|c|c|c|}
\hline & Keruangan & Pelingkup & Struktur \\
\hline D1 & $\begin{array}{l}\text { Menempel } \\
\text { dengan } \\
\text { dinding rumah } \\
\text { induk }\end{array}$ & $\begin{array}{l}\text { Tertutup } \\
\text { dengan } \\
\text { adanya lantai, } \\
\text { dinding, atap }\end{array}$ & $\begin{array}{l}\text { Dinding } \\
\text { semipermanen } \\
\text { dengan kayu } \\
\text { dan atap asbes }\end{array}$ \\
\hline D2 & $\begin{array}{l}\text { Bagian dari } \\
\text { rumah induk } \\
\text { dengan akses } \\
\text { dari dalam } \\
\text { rumah induk } \\
\text { dan dari luar }\end{array}$ & $\begin{array}{l}\text { Tertutup } \\
\text { dengan } \\
\text { adanya lantai, } \\
\text { dinding, atap }\end{array}$ & $\begin{array}{l}\text { Dinding bata } \\
\text { dan } \\
\text { konstruksi } \\
\text { beton } \\
\text { bertulang }\end{array}$ \\
\hline
\end{tabular}

Sumber: Hasil analisis (2016)

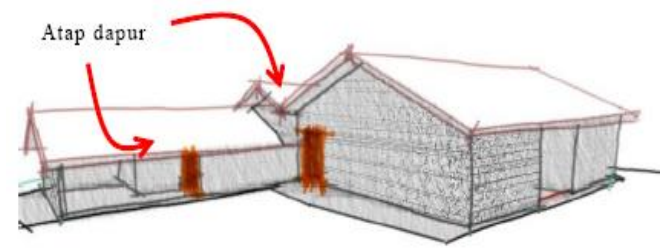

Gambar 16. Posisi dapur Bapak Moh. Baroni

Sumber: Data Nainggolan (2016)

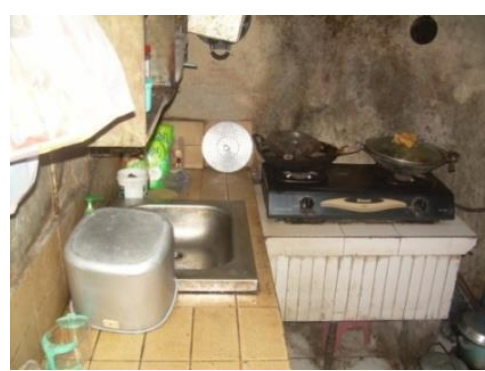

Gambar 17. Dapur Baru Bapak Moh. Baroni

Sumber: Dokumentasi Nainggolan (2012)
Hubungan ruang

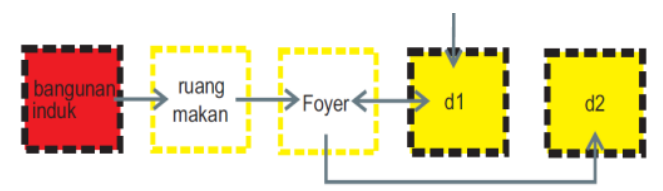

Gambar 18. Hubungan bangunan induk dan dapur

Sumber: Hasil analisis (2016)

Hubungan antara bangunan induk dan ruang-ruang dapur seperti pada Gambar menunjukkan adanya ruang makan dan ruang foyer sebagai ruang perantara antara bangunan induk dan ruang-ruang dapur.

\section{Bapak Mugiyono}

Fungsi dan aktivitas

Lokasi ini terletak di dusun Ngestihardjo, Kecamatan Kasihan Sleman. Sama dengan rumah Bapak Moh Baroni lokasi ini menjadi menarik karena kawasan ini menjadi begitu bertumbuh diawali dengan adanya Perumahan Taman Griya Indah dan Green Garden di tahun 90 an. Lokasi ini menjadi salah satu pilihan karena berkembangnya lokasi ini dengan adanya sekolah (SMAN 3 Bener), perguruan tinggi AA YKP, perumahanperumahan seperti Taman Griya Indah, Tirta Sani, Green Garden, dan Pusat perbelanjaan yaitu Mirota Godean.

Tabel 12. Fungsi ruang dapur keluarga Bapak Mugiyono

\begin{tabular}{clll}
\hline Dapur & $\begin{array}{c}\text { Fungsi } \\
\text { Utama }\end{array}$ & \multicolumn{1}{c}{$\begin{array}{c}\text { Fungsi } \\
\text { sekunder }\end{array}$} & $\begin{array}{c}\text { Fungsi } \\
\text { Penunjang }\end{array}$ \\
\hline D1 & Ruang & Ruang & Ruang \\
& Memasak & Membersihk & Penyimpanan \\
makanan & dan & barang \\
& & mencuci & \\
& & dakanan & \\
& & peralatan & \\
\hline D2 & Ruang & Ruang & Ruang \\
& Memasak & Membersihk & Penyimpanan \\
& makanan & an dan & peralatan \\
& & mencuci & \\
& & makanan & \\
& & dan & \\
& & peralatan & \\
& &
\end{tabular}

Sumber: Hasil Analisis (2016) 


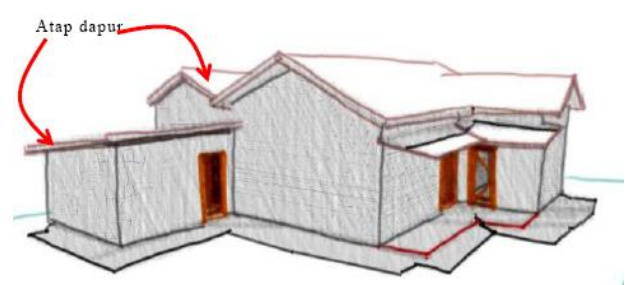

Gambar 19. Posisi dapur Bapak Mugiyono Sumber: Data Nainggolan (2016)

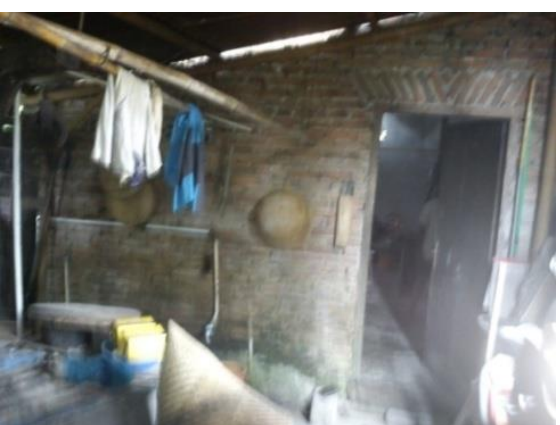

Gambar 20. Dapur Lama Bapak Mugiyono Sumber: Dokumentasi Nainggolan (2012)

Aktivitas utama yang terhubung dengan dapur yaitu: mengambil air, menyediakan bahan bakar, memasak

Bentuk

Tabel 13. Pembentuk ruang dapur keluarga Bapak Mugiyono

\begin{tabular}{llll}
\hline Keruangan & \multicolumn{1}{c}{ Pelingkup } & \multicolumn{1}{c}{ Struktur } \\
\hline D1 & $\begin{array}{l}\text { Menempel } \\
\text { dengan } \\
\text { dinding rumah } \\
\text { induk }\end{array}$ & $\begin{array}{l}\text { Tertutup } \\
\text { dengan } \\
\text { adanya lantai, } \\
\text { dinding, atap }\end{array}$ & $\begin{array}{l}\text { Dinding } \\
\text { semipermanen } \\
\text { dengan seng, } \\
\text { kayu dan atap } \\
\text { asbes }\end{array}$ \\
\hline D2 & $\begin{array}{l}\text { Bagian dari } \\
\text { rumah induk } \\
\text { dengan akses } \\
\text { dari dalam } \\
\text { rumah induk } \\
\text { dan dari dapur } \\
\text { D1 }\end{array}$ & $\begin{array}{l}\text { Tertutup } \\
\text { dengan } \\
\text { adanya lantai, } \\
\text { dinding, atap }\end{array}$ & $\begin{array}{l}\text { Dinding bata } \\
\text { dan } \\
\text { konstruksi } \\
\text { beton } \\
\text { bertulang }\end{array}$ \\
\hline
\end{tabular}

Sumber: Hasil analisis (2016)

Tabel 14. Perletakan sumur, kamar mandi dan bahan bakar terhadap dapur

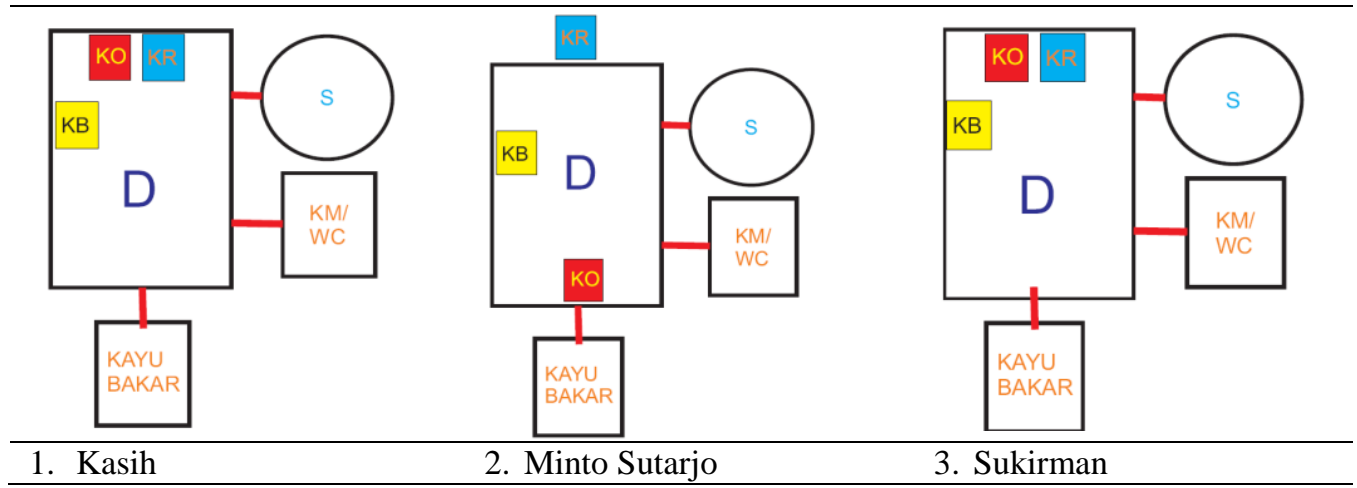

Hubungan Ruang

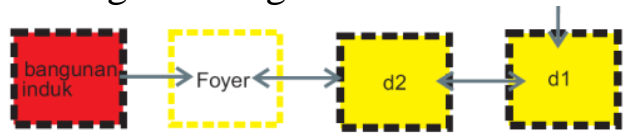

Gambar 21. Hubungan bangunan induk dan dapur keluarga Bapak Mugiyono Sumber: Hasil analisis (2016)

Hubungan antara bangunan induk dan ruang-ruang dapur seperti pada Gambar 21 menunjukkan adanya ruang foyer sebagai ruang perantara antara bangunan induk dan ruang-ruang dapur.

Fungsi dan aktivitas telah mewujud menjadi pemisahan dan penggabungan ruang yang terdeskripsi dalam Tabel 14. Sumur, kamar mandi, dapur serta sumber bahan bakar merupakan unsurunsur yang berhubungan dengan aktivitas.

\section{Diskusi}

\section{Aktivitas dan Fungsi}

Aktifitas dan fungsi merupakan aspek penting yang menentukan kegiatan dan pewadahan ruang dapur. 


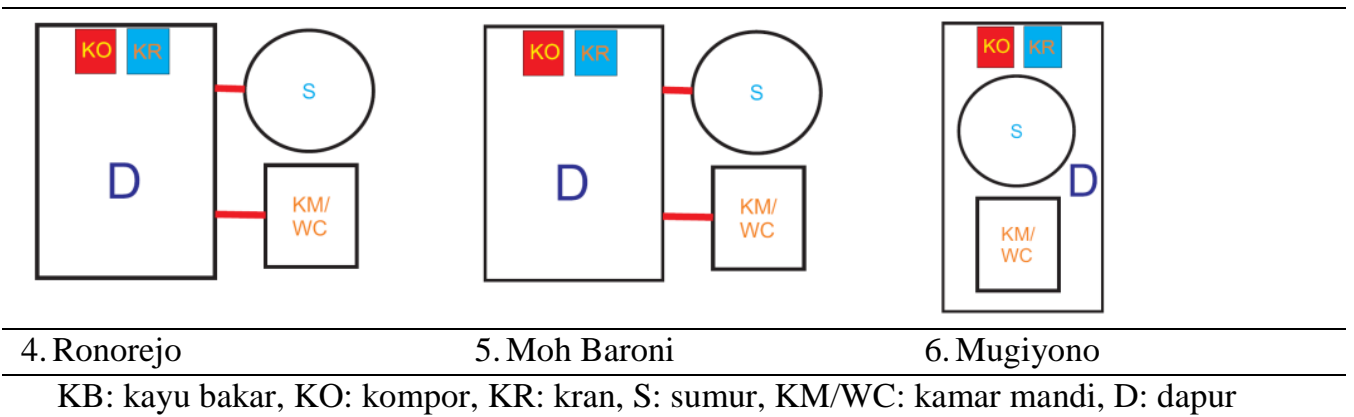

Sumber: Hasil analisis (2016)

Proporsi dapur

Tabel 15. Proporsi dapur

\begin{tabular}{ccc}
\hline Kategori & \multicolumn{2}{c}{ Tipe } \\
\hline Proporsi dapur & $\begin{array}{c}\text { Menjadi } \\
\text { ruang servis } \\
\text { yang } \\
\text { dominan }\end{array}$ & $\begin{array}{c}\text { Menjadi ruang } \\
\text { servis yang tidak } \\
\text { dominan }\end{array}$ \\
\cline { 2 - 3 } & $\mathbf{1 , 2 , 3 , 6}$ & 4,5 \\
\hline
\end{tabular}

Sumber: Hasil analisis (2016)

Fungsi dapur

Tabel 16. Fungsi dapur

\begin{tabular}{cccc}
\hline $\begin{array}{c}\text { Kate } \\
\text { gori }\end{array}$ & & \multicolumn{2}{c}{ Tipe } \\
\hline $\begin{array}{c}\text { Fungsi } \\
\text { dapur }\end{array}$ & $\begin{array}{c}\text { Mencuci, } \\
\text { memasak }\end{array}$ & $\begin{array}{c}\text { Penyimpan- } \\
\text { an kendaraan }\end{array}$ & $\begin{array}{c}\text { Penyimpan- } \\
\text { an Material } \\
\text { dan } \\
\text { peralatan }\end{array}$ \\
\hline & $\mathbf{1 , 2 , 3 , 4 , 5 , 6}$ & $\mathbf{1 , 2}$ & $1,3,5,6$ \\
\hline $\begin{array}{c}\text { Motivasi } \\
\begin{array}{c}\text { Perubahan } \\
\text { dapur }\end{array}\end{array}$ & $\begin{array}{c}\text { Penambah } \\
\text { an ruang }\end{array}$ & Kemudahan & $\begin{array}{c}\text { Kenyaman- } \\
\text { an }\end{array}$ \\
\hline & $\mathbf{1 , 2 , 3 , 6}$ & $\mathbf{4}$ & 5 \\
\hline
\end{tabular}

Sumber: Hasil analisis (2016)

Dapur menjadi ruang tambahan yang selalu berubah berdasarkan kebutuhan. Posisi dapur banyak disesuaikan dengan kebutuhan ruang-ruang pada rumah induk. Dalam pola rumah tradisional dapur merupakan bangunan tersendiri yang menyesuaikan dengan perubahan-perubahan rumah induk. Motivasi perubahan dapur berbagai macam, perubahan ukuran dapur karena ada kebutuhan kamar tidur, perubahan dapur karena rumah lama rusak, perubahan dapur karena penambahan ruang pada rumah induk, Perubahan dapur karena kenyamanan.

Dalam perubahannya dapur yang berubah tetap merupakan ruang servis yang luas dan dominan (Tabel 15). Dominasi itu terjadi karena di dalam dapur diletakkan juga beberapa perangkat lain seperti material, peralatan dan di waktu malam kendaraan (Tabel 16).

Peran dapur

Tabel 17. Peran dapur

\begin{tabular}{lll}
\hline Kategori & Tipe & \\
\hline Peran dapur & $\begin{array}{l}\text { Ruang } \\
\text { makan }\end{array}$ & Ruang penyimpanan \\
\cline { 2 - 3 } & 1,4 & $\mathbf{1 , 2 , 3 , 4 , 5 , 6}$ \\
\hline Sumber: Hasil Analisis $(2016)$
\end{tabular}

Sumber: Hasil Analisis (2016)

Dapur berperan menjadi tempat berkumpul anggota keluarga secara informal. Disediakannya meja dan kursi pada dapur menguatkan indikasi tersebut. Dapur menjadi tempat untuk duduk dan juga menjadi tempat meja makan. Peran yang lebih dominan adalah sebagai ruang penyimpanan (Tabel 17).

\section{Transformasi Bentuk}

Dari bentuk didapatkan pola-pola bentukan baru dengan beberapa kategori. Bentuk yang terjadi akan dilihat dari keterkaitannya dengan fungsi dan aktivitas yang terjadi

\section{Keruangan}

\section{Tabel 18. Keruangan}

\begin{tabular}{ccc}
\hline kategori & \multicolumn{2}{c}{ tipe } \\
\hline $\begin{array}{c}\text { Akses dalam melalui } \\
\text { ruang lain }\end{array}$ & $\begin{array}{l}\text { Ruang } \\
\text { makan }\end{array}$ & foyer \\
\hline & $\mathbf{1 , 2 , 4}$ & $\mathbf{3 , 5 , 6}$ \\
\hline $\begin{array}{c}\text { Akses dari luar } \\
\text { langsung }\end{array}$ & Tapak lain & $\begin{array}{c}\text { Halaman } \\
\text { belakang }\end{array}$ \\
\hline & 3 & $\mathbf{1 , 2 , 4 , 5 , 6}$ \\
\hline
\end{tabular}




\begin{tabular}{ccc}
\hline kategori & \multicolumn{2}{c}{ tipe } \\
\hline Perletakan dapur & $\begin{array}{c}\text { Sebelah } \\
\text { kamar } \\
\text { mandi dan } \\
\text { surmur }\end{array}$ & $\begin{array}{c}\text { Terpisah dari } \\
\text { kamar mandi } \\
\text { dan sumur }\end{array}$ \\
\hline & $\mathbf{1 , 2 , 3 , 6}$ & 4,5 \\
\hline Posisi dapur & $\begin{array}{c}\text { Dibagian } \\
\text { belakang } \\
\text { rumah } \\
\text { induk }\end{array}$ \\
\hline \multicolumn{3}{c}{$\mathbf{1 , 2 , 3 , 4 , 5 , 6}$} \\
\hline
\end{tabular}

Sumber: Hasil analisis (2016)

Dalam konteks ini ruang dipandang sebagai perwujudan kegiatan manusia. Berdasarkan pengamatan dilapangan maka didapatkan beberapa tema. Dalam pengamatan langsung di lokasi pencapaian ke dapur sebagai ruang disatukan dengan rumah induk melalui ruang-ruang penghubung atau ruangruang perantara. Ruang makan sebagai perantara, ruang bebas (foyer). Dapur dianggap memiliki akses langsung dengan luar ketika terdapat sebuah pintu penghubung langsung dengan luar. Akses luar ini disiapkan sebagai penegasan bahwa dapur sebagai ruang belakang yang akan lebih nyaman jika dicapai melalui jalur luar tanpa harus melalui rumah induk. Dalam Santosa (2000) akses ke pintu samping dianggap sebagai akses 'tidak seremonial'. Dalam Tjahjono (1989), umumnya rumah tradisional Jawa meletakkan Sumur pada pojok Timur Laut dan dapur di Utara Tengah. Dapur didekatkan namun dipisahkan dari rumah induk melalui ruang perantara.

Pelingkup

\section{Tabel 19. Pelingkup}

\begin{tabular}{ccc}
\hline kategori & \multicolumn{2}{c}{ tipe } \\
\hline Tertutup masif & $\begin{array}{c}\text { Dengan } \\
\text { dinding } \\
\text { rumah induk } \\
1 \text { sisi }\end{array}$ & $\begin{array}{c}\text { Dengan dinding } \\
\text { rumah induk } \\
\text { lebih dari 1 sisi }\end{array}$ \\
\cline { 2 - 3 } & $\mathbf{1 , 5 , 6}$ & $\mathbf{2 , 3 , 4}$ \\
\hline $\begin{array}{c}\text { Tertutup tidak } \\
\text { masif }\end{array}$ & $\begin{array}{c}\text { Dengan } \\
\text { dinding } \\
\text { rumah induk } \\
1 \text { sisi }\end{array}$ & - \\
\cline { 2 - 3 } & $\mathbf{1 , 2 , 3 , 4 , 5 , 6}$ & - \\
\hline
\end{tabular}

Sumber: Hasil analisis (2016)
Pada bagian ini melihat elemen-elemen yang dapat menentukan pelingkup ruang dan melihat tingkat keterbukaan maupun ketertutupan ruang. Dapur yang tertutup masif dengan dinding bata. Dapur yang tertutup tidak masif adalah dapur tradisional yang ditutup dengan bahan anyaman bambu (gedek).

Struktur

Tabel 20. Struktur

\begin{tabular}{ccc}
\hline kategori & \multicolumn{2}{c}{ tipe } \\
\hline Atap dapur & $\begin{array}{c}\text { Material sama } \\
\text { dengan rumah } \\
\text { induk }\end{array}$ & $\begin{array}{c}\text { Material } \\
\text { berbeda } \\
\text { dengan rumah } \\
\text { induk }\end{array}$ \\
\cline { 2 - 3 } & 2,4 & $\mathbf{1 , 3 , 5 , 6}$ \\
\hline $\begin{array}{c}\text { Struktur utama } \\
\text { bangunan } \\
\text { terpisah }\end{array}$ & $\begin{array}{c}\text { Menempel pada } \\
\text { struktur rumah } \\
\text { induk }\end{array}$ & $\begin{array}{c}\text { Bagian } \\
\text { struktur rumah } \\
\text { induk }\end{array}$ \\
\hline & $\mathbf{1 , 3 , 5 , 6}$ & 2,4 \\
\hline
\end{tabular}

Sumber: Hasil analisis (2016)

Sebagai ruang tambahan dapur memiliki atap tambahan karena biasanya dibangun setelah rumah induk dibangun. Dapur dengan atap tambahan.

Bentuk yang terjadi menyampaikan pesan masih ada perbedaan dapur dengan rumah induk. Baik itu melalui akses maupun struktur dan pelingkupnya. Sebagai bagian yang dibangun setelah omah maka banyak pawon atau dapur ditempelkan pada bangunan induk.

\section{Temuan Elemen Primer yang Memotivasi Transformasi Bentuk}

Elemen primer didapatkan dari aktivitas utama yang terjadi pada dapur. Tjahjono (1989) mengungkapkan dalam urutan pembangunan rumah di Jawa umumnya adalah sumur, omah, gandok timur atau pawon, pendopo, gandok barat. Dapur dan kamar mandi biasanya terletak pada posisi Timur Laut. Lokasinya biasanya bersebelahan dengan sumur karena berhubungan dengan air. Posisi ini dinamakan pekiwon. Diperkuat oleh Sumintarsih 
(1990), dapur pada umumnya terletak di belakang rumah atau di samping rumah. Bangunan dapur yang terletak di belakang rumah maupun di samping rumah, biasanya berupa bangunan yang berdiri sendiri atau sebagian dari rumah induk. Letak arah bangunan dapur pada umumnya mengikuti bangunan rumah induk (terutama untuk bangunan dapur yang berada di luar rumah).

Tabel 21. Aktivitas utama dapur

\begin{tabular}{c|c|c|c|c}
\hline \multicolumn{4}{c}{ AKTIVITAS UTAMA } \\
\hline \multirow{2}{*}{$\begin{array}{c}\text { MENGAMBIL AIR } \\
\text { (sumur dan Kran) }\end{array}$} & \multicolumn{2}{|c|}{$\begin{array}{c}\text { MENGAMBIL BAHAN } \\
\text { BAKAR }\end{array}$} & \multicolumn{2}{c}{ MEMASAK MAKANAN } \\
\cline { 2 - 5 } & Kayu Bakar & Gas & Tungku & Kompor \\
\hline$-1,2,3,4,5,6$ & $-1,2,3$ & $-1,2,3,4,5,6$ & $-1,2,3,6$ & $-1,2,3,4,5,6$ \\
\hline
\end{tabular}

Sumber: Hasil analisis (2016)

Dari pewadahan fungsi yang terjadi, temuan elemen primer dalam transformasi bentuk dasar ini ternyata memiliki keterkaitan yang kuat dengan unsur-unsur utama yang khas pada dapur yaitu air dan api. (Tabel 21). Mengambil air, mengambil bahan bakar dan memasak makanan berhubungan dengan air dan api. Perubahan pemakaian air dari menimba sumur menjadi memakai kran, bahan bakar dari kayu bakar menjadi gas elpiji, memasak dari memakai tungku menjadi kompor, mendorong terjadinya bentuk baru yang tertutup, mendekat ke rumah induk namun masih dipisahkan secara struktural., elemen lantai dapur yang mewadahi pemakaian gas elpiji dan kompor.

\section{Temuan penerapan kitchen work triangle dalam transformasi bentuk}

Efisiensi dan sanitasi adalah highlights dari desain dapur pada awal abad ke20. Dapur Keluarga merupakan ruang kunci pada sebuah rumah. Dapur disini bukan hanya untuk memasak dan makan, tapi juga berfungsi untuk mengawasi anak-anak dalam aktivitas mereka. Jenis dapur ini berada dalam posisi yang tidak jauh dari pintu luar. Sehingga memudahkan dalam membawakan barang belanjaan (Powell, 2005). Efisiensi kerja dan juga ergonomis menjadi penekanan penggunaan dapur modern. (Gambar 2) Relasi tiga aktivitas dengan tiga peralatan ini adalah prinsip dapur modern yaitu: menyimpan dan mengawetkan, memasak, dan mencuci. Mengamati pola pewadahan aktivitas pada Tabel 14 dan Tabel 21, ditemukan ada aktivitas penting yang terjadi didapur :

1. Mengambil air

2. Mengambil bahan bakar

3. Memasak makanan

Tiga aktivitas di atas berhubungan dengan sumber air, sumber api dan alat memasak. Sumur sebagai sumber air, tempat kayu bakar sebagai sumber bahan bakar dan tungku untuk memasak makanan. Dapur lama menjaga kedekatan antara sumur, kayu bakar dan tungku. Sehingga dapur sebagai ruang yang mewadahi mendekat dengan sumber air. Globalisasi dengan kemajuan teknologi memungkinkan bergeraknya posisi dapur dari dekat dengan sumur menjadi mendekat pada rumah induk. Pada Tabel 14 tiap dapur telah memiliki kran air sebagai sumber air. Jarak dengan sumber air tidak berpengaruh lagi karena telah terhubungnya kran air dengan sumur melalui pipa air bersih. 
Pemakaian kompor yang diletakkan diatas lantai mengakomodir kenyamanan memasak. Hal ini menunjukkan semakin terpisahnya kompor dari kayu bakar sebagai sumber bahan bakar digantikan dengan elpiji sebagai sumber bahan bakar yang didekatkan dengan kompor dan rumah induk. Maka ruang pun menjadi lebih tertutup karena semakin minimnya asap dari bahan bakar yang baru tersebut. Kitchen work triangle telah mewujud dengan adanya kompor, kran dan ruang penyimpanan.

\section{Kesimpulan dan Saran}

Dapur didekatkan namun dipisahkan dari rumah induk melalui ruang perantara. Transformasi bentuk terjadi dengan bertambahnya dapur baru yang mendekat ke rumah induk namun tetap dibatasi dengan ruang perantara. Akses menuju dapur tetap terbatas bagi pemilik rumah. Indikasi itu terlihat dengan adanya pintu samping maupun ruang perantara untuk menuju dapur.

Prinsip ergonomis dengan kitchen work triangle sebagai prinsip dapur modern diterapkan dengan terhubungnya sumber air melalui pipa dan kran. Mendekatkan sumber api dengan sumber bahan bakar dengan memakai kompor dan gas elpiji. Penyimpanan dalam cara yang berbeda terjadi didapur. Ini mendasari ruang dapur yang mendekat ke rumah induk.

\section{Daftar Pustaka}

Giddens, A. (1991). The consequences of modernity, Dalam Melluish, S. (2014). Globalization, culture and psychology. International review of psychiatry, 26(5), 538-543. doi:10.3109/09540261.2014.91 8873

Guardian (2013). Edward Snowden: the whistleblower behind the NSA surveillance revelations. Dalam Melluish, S. (2014). Globalization, culture and psychology. International review of psychiatry, 26(5), 538-543.

Habraken, N. J. (1976). Transformasi bentuk dan ruang pada rumah toko di Kawasan Pecinan Makassar (1970-2005). Dalam Pakilaran, A.U. (2006) Tesis Institut Teknologi Bandung (tidak dipublikasikan).

Jenkins, T. S. (2011). The culture of the kitchen: Recipes for transformative education within the African American cultural experience. About Campus, 16(2), 11-19. doi:10.1002/abc.20056

Johansson, K., Lundberg, S., \& Borell, L. (2011). The cognitive kitchen - key principles and suggestions for design that includes older adults with cognitive impairments as kitchen users. Technology \& Disability, 23(1),2940.doi:10.3233/TAD-20110310

Kitchen (2011). Columbia Electronic Encyclopedia, 6th Edition, 1.

Leupen, B. et al (1997). Design and analysis. New York: Van Nostrand Reinhold, New York.

Margana, S., \& Nursam, M. (Eds.), (2010). Kota-kota di Jawa: Identitas, gaya hidup, dan permasalahan sosial.

Melluish, S. (2014). Globalization, culture and psychology. International Review Of Psychiatry, 26(5), 538-543. 
doi:10.3109/09540261.2014.91 8873

Nainggolan, F. M. R. (2014). Transformasi dapur dalam globalisasi dikaitkan dengan gaya hidup penghuni. Studi kasus: Perumahan Merapi View Ngaglik Sleman. Prosiding Seminar Nasional Peranan Sains dan Teknologi untuk mendukung Pembangunan Berkelanjutan, Kupang, 15-16 Oktober 2014.

Powell C. B. (2005). Architect's pocket book of kitchen design. Architectural Press, an imprint of Elsevier Linacre House. Jordan Hill, Oxford OX2 8DP 30 Corporate Drive, Burlington, MA 01803

Salura, P. (2010). Arsitektur yang membodoh-kan. Bandung: Cipta Sastra Salura.

Sumintarsih, Wibowo, H.J., Herawati I., dkk (1990). Dapur dan alatalat memasak tradisional daerah istimewa Yogyakarta. Departemen Pendidikan Kebudayaan Propinsi Daerah Istimewa Yogyakarta

Tjahjono, G. (1989) Cosmos, center, and duality in Javanese architectural tradition: The symbolic dimensions of house shapes in Kota Gede and surroundings. Disertasi University of California at Berkeley (tidak dipublikasikan).

Yunus, H. S. (1987). Beberapa determinan perkembangan permukiman kota (dampak dan pengelolaannya). Fakultas Geografi Universitas Gadjah Mada.

Yunus, H.S. (1987). Permasalahan daerah urban fringe dan alternative pemecahannya.
Fakultas Geografi Universitas Gadjah Mada. 